\title{
Lotus tetragonolobus, Ulex europaeus, Maackia amurensis, and Arachis hypogaea (peanut) lectins influence the binding of Helicobacter pylori to gastric carbohydrates
}

\author{
Iwona Radziejewska ${ }^{1, A, B, D-F}$, Małgorzata Borzym-Kluczyk ${ }^{2, C, D}$, Katarzyna Leszczyńska ${ }^{3, B, D}$ \\ ${ }^{1}$ Department of Medical Chemistry, Medical University of Bialystok, Poland \\ ${ }^{2}$ Department of Pharmaceutical Biochemistry, Medical University of Bialystok, Poland \\ ${ }^{3}$ Department of Microbiology, Medical University of Bialystok, Poland \\ A - research concept and design; $\mathrm{B}$ - collection and/or assembly of data; $\mathrm{C}$ - data analysis and interpretation; \\ $D$ - writing the article; $E$ - critical revision of the article; $F$ - final approval of the article
}

Address for correspondence

Iwona Radziejewska

E-mail: iwona@umb.edu.pl

Funding sources

This work was supported by Medical University of Białystok grant No. 143-03753F. This study was conducted with the use of equipment purchased by the Medical University of Bialystok as part of the OP DEP 2007-2013, Priority Axis 1.3, contract No. POPW.01.03.00-20-008/09.

Conflict of interest

None declared

Acknowledgements

We would like to express our great appreciation to prof. Z. Namiot from the Department of Physiology, Medical University of Bialystok, for the provision of clinical material for our research.

Received March 22, 2016

Reviewed June 15, 2016

Accepted February 14, 2017

\begin{abstract}
Background. The carbohydrates of gastric mucins and other sugar structures are involved in interactions with Helicobacter pylori (H. pylori) adhesins. The binding of bacteria to mucins can protect the epithelium from direct contact with the pathogen and from developing infection because of a specific barrier created by the mucus. The pathogen also interacts with other carbohydrate structures of the epithelium. Direct contact between the bacteria and the epithelial cells facilitates infection development.

Objectives. The aim of this study was to assess the influence of Maackia amurensis (MAA), Lotus tetragonolobus (LTA), Ulex europaeus (UEA), and Arachis hypogaea (PNA) lectins on the binding of gastric carbohydrates with H. pylori adhesins.
\end{abstract}

Material and methods. Three patients' gastric juices and $12 \mathrm{H}$. pylori strains were included in the study. An ELISA test was used to assess the presence of MUC1 and MUC5AC mucins and the sugar structures recognized by all examined lectins. The binding of the bacterium to the sugar structures was analyzed by the ELISA method with and without the gastric juices pretreated with lectins.

Results. In the majority of the samples examined, MAA, LTA, UEA, and PNA lectins enhanced the binding of $\mathrm{H}$. pylori to specific carbohydrate structures of gastric mucins.

Conclusions. Substances which influence the binding of the pathogen with specific carbohydrate receptors on gastric epithelial cells can favor inflammation development. However, if H. pylori binds with mucins, the bacterium can have difficulty reaching the epithelium and progressing with infection.

Key words: Helicobacter pylori, mucins, lectins

DOI

10.17219/acem/68987

Copyright

Copyright by Author(s)

This is an article distributed under the terms of the

Creative Commons Attribution Non-Commercial License

(http://creativecommons.org/licenses/by-nc-nd/4.0/) 


\section{Introduction}

Helicobacter pylori, a Gram-negative bacterium, colonizes the human stomach of more than $50 \%$ of the world's population. It is said to be the most globally common bacterial infectious agent. $H$. pylori can cause chronic active gastritis, peptic ulceration, and gastric cancers. It is interesting that more than $80 \%$ of infected individuals remain asymptomatic. ${ }^{1,2}$

The mucosal surface, with its mucus layer constantly secreted by the epithelial cells, plays an important role in the protection of the human stomach against invading pathogens. The mucus layer is mainly comprised of 2 secreted mucins: MUC5AC and MUC6, the first produced by the surface epithelium and the second one by the glands. ${ }^{3,4}$ There is also MUC1, the most highly expressed membrane-tethered mucin that is normally found on the apical surface of polarized epithelia, and is a major component of glycocalyx. It can initiate a signaling pathway in response to bacterial invasion and is thought to play an important role in cell-cell and cell-extracellular matrix interactions. ${ }^{5-7}$ Mucins are heavily glycosylated glycoproteins with a large number of O-linked oligosaccharides with many sugar antigens which can be recognized by $H$. pylori adhesins. ${ }^{8,9}$ It has been suggested that the bacterium can bind to both MUC1 and MUC5AC mucins via fucosylated and sialylated glycans. ${ }^{10-12}$ Some authors suggest that a release of MUC1 following the binding to $H$. pylori can limit the adhesion of the bacterium to the cell surface. Besides, MUC1 forms a physical barrier and may protect the gastric epithelium from adhesion to non-mucin binding agents. ${ }^{13}$

The involvement of MUC1 and MUC5AC mucins in $H$. pylori infection development seems to be unquestionable. To prove the participation of mucin sugar antigens in binding with $H$. pylori adhesins, some substances which can inhibit or enhance interactions between bacteria and mucins can be used. ${ }^{14}$ Anti-Lewis-x antibodies have been suggested as agents promoting $H$. pylori adhesion to gastric epithelial cells. ${ }^{15}$ Our latest studies with anti-Lewis-b, anti$\mathrm{H}$ type 1 , and sialyl Lewis- $\mathrm{x}$ revealed the slight inhibitory effect of these antibodies on $H$. pylori binding to MUC1 mucin. ${ }^{16}$ In the presented study, we used specific plant lectins in order to check their influence on $H$. pylori adhesion to gastric carbohydrates.

It seems clear that the explanation of the strategy used by $H$. pylori for colonizing the gastric epithelium could help reveal how pathogens overcome specific barriers to infection, such as the mucus layer. ${ }^{17}$

\section{Material and methods}

\section{Patients and specimens}

The gastric juices (as the source of mucins) of 3 H. pyloriinfected patients with duodenal ulcers were included in the study. The patients were hospitalized in the Department of Medicine and Gastroenterology of the Regional Hospital of Bialystok, Poland. They were treated for 2 weeks by oral administration of omeprazole $(2 \times 20 \mathrm{mg}$ per day), amoxicillin $(2 \times 100 \mathrm{mg})$, and tynidazole $(2 \times 500 \mathrm{mg})$. Gastric juices were taken on days 11-13 of the successful treatment. The presence of $H$. pylori was examined histopathologically and by the urease test with gastric cells scraped under endoscopic examination.

To obtain high-molecular-mass mucins, the juices were pretreated as described before. ${ }^{18}$ The prepared samples of the juices were diluted to the same protein concentration $(0.005 \mathrm{mg} / \mathrm{mL})$ prior to further tests. The protein content was measured using the bicinchoninic acid method. ${ }^{19}$

\section{Bacterial strains and culture conditions}

Helicobacter pylori strains were isolated from the gastric epithelial cells of 12 patients suffering from gastritis. The scrapings were collected before the beginning of the treatment, under endoscopic examination, from the prepyloric area and the body of the stomach. The scrapings were immediately carried into the transport medium Portagerm pylori (bioMerieux, Marcy-l'Étoile, France). Then, after homogenization, the bacteria were cultured on Pylori Agar and Columbia Agar supplemented with 5\% sheep blood (bioMerieux, France) for 7 days at $37^{\circ} \mathrm{C}$ under microaerophilic conditions using a Genbag microaer (bioMerieux, Marcy-l'Étoile, France). Microorgansms were identified upon the colony morphology by the Gram method. Additionally, the activity of the bacterial urease, catalase and oxidase were also determined. To prove $H$. pylori species, the ELISA test (HpAg48; EQUIPAR, Guadalajara, Mexico) was used. Then, the bacteria were subcultured in the same conditions and suspended at $1.2 \times 10^{9}$ bacteria $/ \mathrm{mL}$ in PBS.

\section{Determination of MUC1, MUC5AC and sugar antigens recognized by Lotus tetragonolobus, Ulex europaeus, Maackia amurensis, and Arachis hypogaea lectins in gastric juices}

Aliquots $(50 \mu \mathrm{L})$ of the samples of gastric juices (containing $0.005 \mathrm{mg}$ of protein $/ \mathrm{mL}$ ) were coated onto microtiter plates (NUNC F96; Maxisorp, Roskilde, Denmark) at room temperature (RT) overnight. The plates were washed 3 times $(100 \mu \mathrm{L})$ in the washing buffer PBS-T (PBS, 0.05\% Tween, Sigma, St. Luis, USA) between all ensuing steps. Unbound sites were blocked with $100 \mu \mathrm{L}$ of $1 \%$ blocking reagent for ELISA (Roche Diagnostics, Mannheim, Germany) for $1 \mathrm{~h}$. Then the plates were incubated ( $2 \mathrm{~h}$ at RT) with $100 \mu \mathrm{L}$ of anti-MUC1 and anti-MUC5AC monoclonal antibodies (for specifications and dilutions of antibodies, see Table 1) diluted in $1 \%$ bovine serum albumin (BSA) in PBS-T or with biotinylated Lotus tetragonolobus (LTA), Ulex europaeus (UEA), Maackia amurensis (MAA), or 
Table 1. Specifications of antibodies used in the study

\begin{tabular}{|l|c|c|}
\multicolumn{1}{|c|}{ Antibody } & Clone & Source \\
\hline Anti-MUC1 & BC2 & Thermo Scientific \\
Anti-MUC5AC & $45 \mathrm{M} 1$ & Sigma \\
Anti-H.pylori (polyclonal, biotin-conjugated) & & Abcam \\
Horseradish peroxidase conjugated anti-mouse lgG & Sigma & $1: 400$ \\
\hline
\end{tabular}

Table 2. The major binding specifications of lectins used in the study

\begin{tabular}{|l|c}
\hline \multicolumn{1}{|c|}{ Origin and abbreviations of lectins } & Binding preferences \\
\hline Lotus tetragonolobus (LTA) & Fuca1-3GlcNAc \\
Ulex europaeus (UEA) & Fuca1-2Gal; Fuca1-3GIcNAc \\
Maackia amurensis (MAA) & NeuAca2-3Gal \\
Arachis hypogaea (peanut) (PNA) & Galß1-3GalNAC \\
\hline
\end{tabular}

Arachis hypogaea (PNA) lectins (diluted to $5 \mu \mathrm{g}$ of lectin/mL in PBS-T-BSA (1\%)) (Vector, Burlingame, USA) (for carbohydrate specifications of lectins, see Table 2). The lectin solutions were supplemented with metal cations: LTA, UEA, and PNA with $0.1 \mathrm{mmol} / \mathrm{L} \mathrm{CaCl}_{2}$; MAA with $0.1 \mathrm{mmol} / \mathrm{L} \mathrm{CaCl}_{2}$ and $0.01 \mathrm{mmol} / \mathrm{L} \mathrm{MnCl}_{2}$. Then the plates were incubated ( $2 \mathrm{~h}$ at RT) with $100 \mu \mathrm{L}$ of secondary, rabbit anti-mouse IgG horseradish peroxidase (conjugated for MUC1 and MUC5AC detection) or with $100 \mu \mathrm{L}$ of horseradish peroxidase avidin D (Vector, Burlingame, USA) (for lectin detection) diluted $(1: 2,000)$ in PBS-T-BSA (1\%). Next, after washing 4 times in PBS, the colored reaction was developed by incubation with $100 \mu \mathrm{L}$ of 2,2'-azino-bis(3-ethylbenzthiazoline-6-sulfonic acid) (ABTS) - the liquid substrate for horseradish peroxidase (Sigma, St. Louis, USA). Absorbance at $405 \mathrm{~nm}$ was measured after about 30-40 min. For controls, wells with no gastric juices were used. The test was performed twice with 3 replicates of each sample.

\section{Binding of $H$. pylori to mucins}

Aliquots of the samples of gastric juices were coated onto microtiter plates and incubated as described above. Then the plates were washed and blocked as before. The plates were incubated for $2 \mathrm{~h}$ at RT with aliquots $(100 \mu \mathrm{L})$ of nonbiotinylated LTA, UEA, MAA, and PNA lectins. Two concentrations of lectin were used (in PBS supplemented with metal cations - see above): 40 and $0.4 \mu$ g of lectin $/ \mathrm{mL}$ of PBS-T-BSA (1\%). Wells without added lectins served as controls. The bacteria were diluted with PBS to get $2.4 \times 10^{7}$ cells $/ \mathrm{mL}$ and $100 \mu \mathrm{L}$ of each strain solution were added to the wells and incubated at $37^{\circ} \mathrm{C}$ overnight. Then the wells were treated with anti-H. pylori polyclonal, biotin-conjugated antibody diluted with PBS-T-BSA (1\%) at RT for $1 \mathrm{~h}$. After being incubated with horseradish peroxidaseconjugated avidin $\mathrm{D}$, the colored reaction was developed as described above.

\section{Statistics}

The binding of $H$. pylori to mucins of gastric juices (pretreated with lectins or not) was subjected to statistical analysis (using STATISTICA v. 10.1 (StatSoft, Tulsa, USA). The results are presented as mean \pm SD. Post hoc analysis calculated by an NIR test was used. Statistical significance was assumed at $\mathrm{p}<0.05$.

The study was approved by the Institutional Ethical Committee with the principles of the Declaration of Helsinki and informed consent was obtained from all patients.

\section{Results}

Three examined gastric juices revealed the presence of MUC1 and MUC5AC mucins. Mucin expressions were determined as OD values (405 nm) in the ELISA test (Fig. 1).

Figure 2 shows the expression of specific carbohydrate structures on gastric glycoproteins, recognized by the examined lectins. Fuc linked by $\alpha 1-2$ bond to Gal or by $\alpha 1-3$ bond to GlcNAc, recognized by the UEA lectin is observed at the highest level. A high level of sialic acid linked by $\alpha 2-3$ bond to Gal, recognized by the MAA lectin, is also seen. Fuc linked by $\alpha 1-3$ to GlcNAc, recognized by the LTA lectin and the Gal $\alpha 1-3$ GalNAc structure, recognized by the PNA lectin, are observed at a much lower level.

The abovementioned lectins were used to check their influence on the binding of $H$. pylori to gastric mucins. Two concentrations of lectins were used: 40 and $0.4 \mu \mathrm{g} / \mathrm{mL}$. In Fig. 3 we can observe that in all samples, the addition of UEA, MAA and PNA lectins (at a higher concentration) caused an increase in the binding of the bacterium

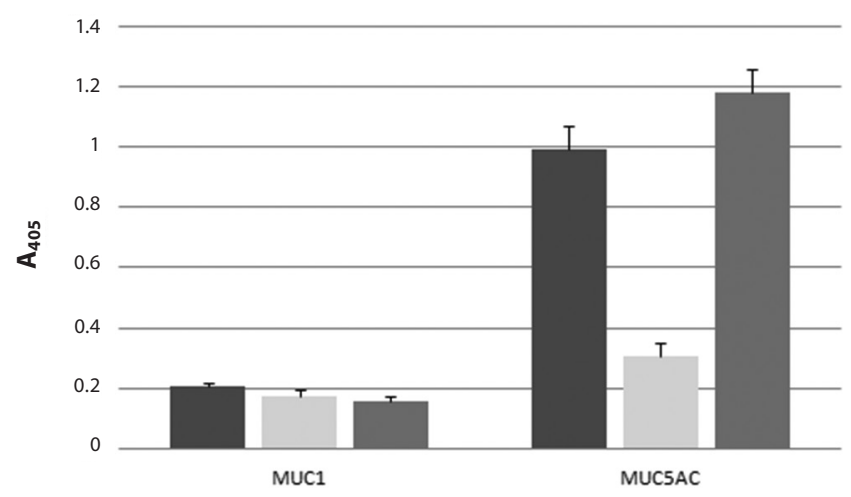

Fig. 1. The level of MUC1 and MUC5AC mucins in the gastric juices of 3 patients (each bar represents an individual patient); data is presented as the mean of 6 replicates \pm SD 

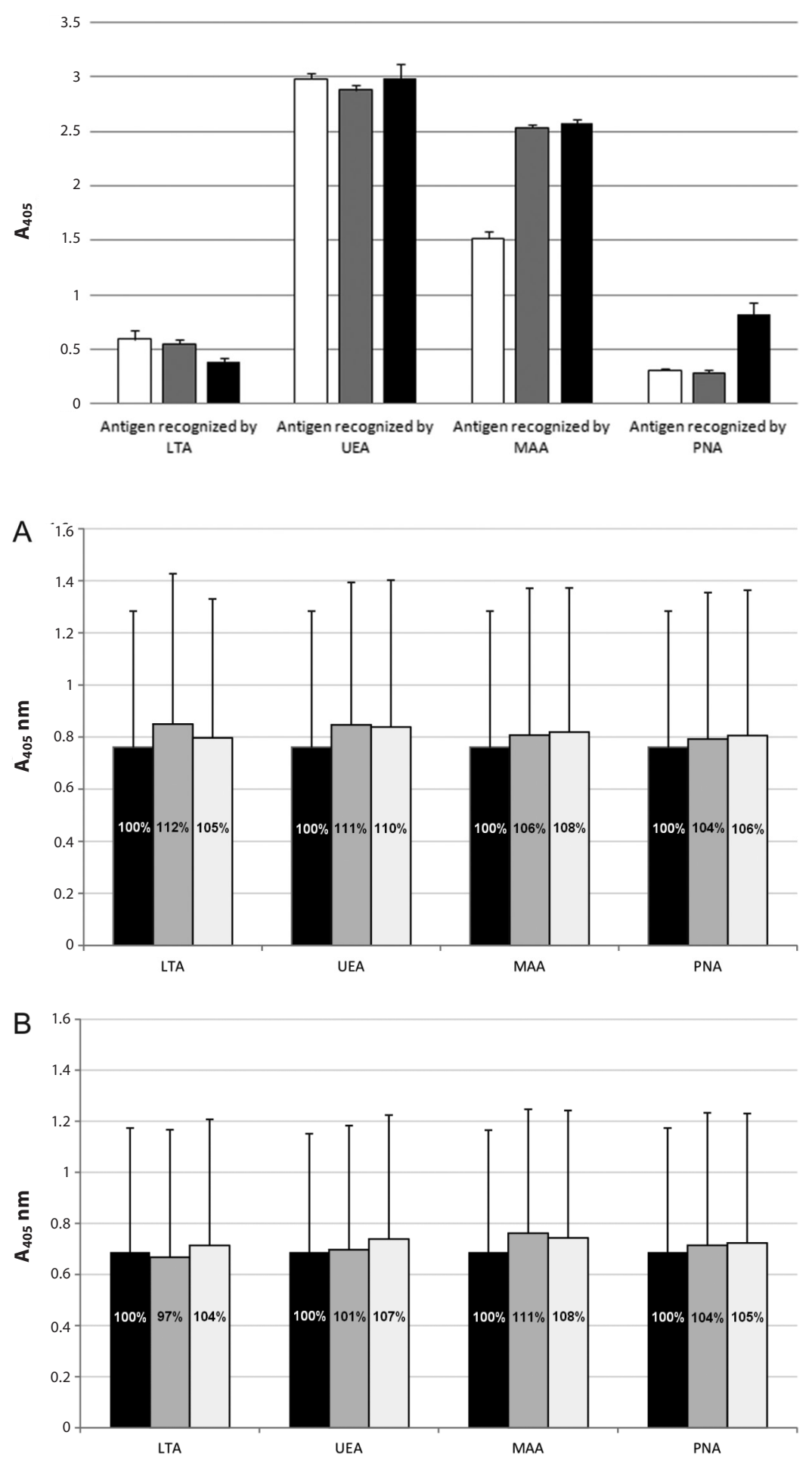

Fig. 2. The level of specific carbohydrate antigens (in the 3 examined gastric juices) recognized by LTA, UEA, MAA, and PNA lectins (bars represent individual patients); data is presented as the mean of 6 replicates \pm SD
Fig. 3. LTA, UEA, MAA, and PNA lectins' additive effect on Helicobacter pylori's binding to gastric mucins

H. pylori $(n=12)$ was allowed to react with gastric mucins and the bound bacterium was assessed with polyclonal anti-H. pylori antibodies; black bars - samples without lectins; grey bars - samples treated with $40 \mathrm{\mu g} / \mathrm{mL}$ of specified lectins; white bars - samples treated with $0.4 \mu \mathrm{g} / \mathrm{mL}$ of specified lectins; $A, B, C$ - results for individual patients; binding of $\mathrm{H}$. pylori without pretreatment with lectins (black bars) is stated as 100\%; bars represent \pm SD to mucins. In the case of the LTA lectin, only in one sample (Fig. 3b) was a slight decrease in $H$. pylori binding observed for a lectin concentration of $40 \mu \mathrm{g} / \mathrm{mL}$. Generally, it can be seen that a smaller dose of lectins $(0.4 \mu \mathrm{g} / \mathrm{mL})$ induced less of an increase in bacterium binding.

\section{Discussion}

Secretory MUC5AC and epithelial MUC1 mucins, with their specific carbohydrate structures, are said to be involved in interactions with $H$. pylori adhesins. ${ }^{12,13}$ Some authors imply that Lewis antigens on the lipopolysaccharide (LPS) of $H$. pylori are also involved in bacterial adhesion. ${ }^{15}$ However, the exact mechanism of interaction of $H$. pylori with the gastric epithelium still needs to be more precisely elucidated.

Some tested particles have been shown to inhibit or enhance the binding of the bacterium to epithelial carbohydrate antigens. It was revealed that anti-Le x MAb could promote the adhesion ability of an $H$. pylori strain with 
high Le $\mathrm{x}$ expression. ${ }^{15}$ According to the authors, MAb can serve as a kind of bridge to connect the Le $\mathrm{x}$ antigen of bacteria and the Le $\mathrm{x}$ antigen of the epithelium. These results are not in accordance with our latest studies with anti-Lewis b, anti-H type 1, and sialyl Lewis $\mathrm{x}$ antibodies. We revealed that the antibodies in question slightly inhibited the binding of bacteria to the MUC1 mucin. ${ }^{16}$ In other studies, it was observed that neoglycoproteins of the Le b or sLe $\mathrm{x}$ oligosaccharides conjugated to human serum albumin (HSA) inhibited the adhesion of $H$. pylori to the gastric mucosa in vitro. ${ }^{9,20}$ Glycoconjugates of porcine milk also showed the inhibition of $H$. pylori adhesion. ${ }^{21}$ These findings give more insight into the participation of peculiar sugar structures in interactions with bacterial adhesins. The exact elucidation of the mechanisms that $H$. pylori uses to colonize mucosal surfaces could lead to a complete understanding of how pathogens overcome barriers to infection, such as the presence of a mucus layer.

The lectins isolated from certain plants which were used in our study are able to recognize specific sugar structures in a manner similar to antigen-antibody interactions. Some lectins require that the particular sugar be in a terminal non-reducing position in the oligosaccharide; others can bind to sugars within the oligosaccharide chain. The affinity between a lectin and its receptor may vary a great deal due to small changes in the carbohydrate structure of the receptor. ${ }^{22}$

In our study, we decided to use lectins that can recognize sugar structures which are said to act as carbohydrate receptors for H. pylori adhesins (LTA, UEA, or MAA) or are part of mucin structures (PNA) (Table 2). All the lectins used revealed the enhancement of $H$. pylori binding to gastric mucins. Despite the different levels of sugar structures in gastric juices recognized by lectins, the increased binding effect was similar in all of the samples. It can suggest that some non-specific interaction between lectins and carbohydrate structures in gastric juices are possible. The eventual participation of bacterial LPS carbohydrates in such interactions cannot be excluded. The lectins used, with their high affinity to specific sugar antigens, can act as agents which could crosslink bacterial and mucin carbohydrates, as well as other sugar structures of the gastric epithelium. The binding of the bacterium with mucins can protect the host from developing an infection because the pathogen would be trapped in mucus and washed away from the stomach. On the other hand, interactions of $H$. pylori with surface carbohydrates could favor infection development by direct interactions of the bacterium with the epithelium.

We want to emphasize that our study should be treated as a preliminary one. More detailed experiments are planned for the future in order to explore the subject more deeply.

\section{References}

1. Atherton JC. The pathogenesis of Helicobacter pylori induced gastro-duodenal diseases. Annu Rev Pathol. 2006;1:63-96.

2. Lillehoj EP, Guang W, Ding H, Czinn SJ, Blanchard TG. Helicobacter pylori and gastric inflammation: Role of MUC1 mucin. J Pediatr Biochem. 2012;2:125-132.

3. Lacunza E, Bara J, Segal-Eiras A, Croce MV. Expression of conserved mucin domains by epithelial tissues in various mammalian species. Res Vet Sci. 2009;86:68-77.

4. Navabi N, Johansson MEV, Raghavan S, Linden SK. Helicobacter pylori infection impairs the mucin production rate and turnover in the murine gastric mucosa. Infect Immun. 2013;81:829-837.

5. Guang W, Czinn SJ, Blanchard TG, Kim KC, Lillehoj EP. Genetic regulation of MUC1 expression by Helicobacter pylori in gastric cancer cells. Biochem Biophys Res Commun. 2014;445:145-150.

6. Guang W, Ding H, Czinn SJ, Kim KC, Blanchard TG, Lillehoj EP. Muc1 cell surface mucin attenuates epithelial inflammation in response to a common mucosal pathogen. J Biol Chem. 2010;285:20547-20557.

7. Jonckheere $\mathrm{N}$, Van Seuningen J. The membrane-bound mucins: From cell signaling to transcriptional regulation and expression in epithelial cancers. Biochimie. 2010;92:1-11.

8. Ilver D, Arnqvist A, Ogren J, et al. Helicobacter pylori adhesion binding fucosylated histo-blood group antigens revealed by retagging. Science. 1998;279:373-377.

9. Mahdavi J, Sonden B, Hurtig M, et al. Helicobacter pylori SabA adhesion in persistent infection and chronic inflammation. Science. 2002; 297:573-578.

10. Linden S, Mahdavi J, Hedenbro J, Boren T, Carlstedt I. Effects of pH on Helicobacter pylori binding to human gastric mucins: Identification of binding to non-MUC5AC mucins. Biochem J. 2004;384:263270.

11. Linden S, Nordman H, Hedenbro J, Hurtig M, Boren T, Carlstedt I. Strain- and blood group-dependent binding of Helicobacter pylori to human gastric MUC5AC glycoforms. Gastroenterology. 2002;123: 1923-1930.

12. Linden SK, Wickstrom C, Lindell G, Gilshenan K, Carlstedt I. Four models of adhesion are used during Helicobacter pylori binding to human mucins in the oral and gastric niches. Helicobacter. 2008;13:81-93.

13. Linden SK, Sheng YH, Every AL, et al. MUC1 limits Helicobacter pylori infection both by steric hindrance and by acting as a releasable decoy. PLoS Pathog. 2009;5:e1000617.

14. Radziejewska I, Borzym-Kluczyk M, Leszczyńska K. Are Lewis b and $\mathrm{H}$ type 1 on Helicobacter pylori involved in binding of bacteria to MUC1 mucin? Adv Clin Exp Med. 2013;22:347-353.

15. Sheu S, Sheu B, Yang $H$, Lei $H$, Wu J. Anti-Lewis $x$ antibody promotes Helicobacter pylori adhesion to gastric epithelial cells. Infect Immun. 2007;75:2661-2667.

16. Radziejewska I, Leszczyńska K, Borzym-Kluczyk M. Influence of monoclonal anti-Lewis $\mathrm{b}$, anti-H type 1 , and anti-sialyl Lewis $\mathrm{x}$ antibodies on binding of Helicobacter pylori to MUC1 mucin. Mol Cell Biochem. 2014;385:249-255.

17. Dolan B, Naughton J, Tegtmeyer N, May FEB, Clyne M. The interaction of Helicobacter pylori with the adherent mucus gel layer secreted by polarized HT29-MTX-E12 cells. PLoS One. 2012;7:e47300.

18. Radziejewska I, Leszczyńska K, Borzym-Kluczyk M, Namiot Z. Assessment of interactions between mucins of gastric juice and Helicobacter pylori - preliminary study. Hepatogastroenterology 2010;57: 367-371.

19. Smith PK, Krohn RJ, Hermanson GT, et al. Measurement of protein using bicinchoninic acid. Anal Biochem. 1985;150:76-85. [Erratum: Anal Biochem. 1987;163:279]

20. Younson J, O'Mahony R, Liu H, et al. A human domain antibody and Lewis $\mathrm{b}$ glycoconjugate that inhibit binding of Helicobacter pylori to Lewis b receptor and adhesion to human gastric epithelium. $J$ Inf Dis. 2009;200:1574-1582. [Erratum: J Infect Dis. 2010;201:481]

21. Gustafsson A, Hultberg A, Sjostrom R, et al. Carbohydrate-dependent inhibition of Helicobacter pylori colonization using porcine milk. Glycobiology. 2006;16:1-10.

22. Liener IE, Sharon N, Goldstein IL. The Lectins. Properties, Functions and Applications in Biology and Medicine. Orlando: Academic Press;1986. 